\title{
Effects of Enhanced Depression Treatment on Diabetes Self-Care
}

\author{
Elizabeth H. B. Lin, MD, MPH \\ Wayne Katon, $M D^{2}$ \\ Carolyn Rutter, $P b D^{1}$ \\ Greg E. Simon, $M D, M P H^{1}$ \\ Evette J. Ludman, $P b D^{1}$ \\ Michael Von Korff, ScD ${ }^{1}$ \\ Bessie Young, $M D, M P H^{3}$ \\ Malia Oliver, $B A^{1}$ \\ Paul C. Ciechanowski, MD, MPH ${ }^{2}$ \\ Leslie Kinder, $\mathrm{PbD}$ \\ Edward Walker, $M D, M P H^{2}$ \\ ${ }^{1}$ Center for Health Studies, Group \\ Health Cooperative, Seattle, Wash \\ ${ }^{2}$ Department of Psychiatry \& Behavioral \\ Sciences, University of Washington \\ School of Medicine, Seattle, Wash \\ ${ }^{3}$ Department of Medicine, Veterans \\ Administration Hospital, and the University \\ of Washington, Seattle, Wash
}

Conflicts of interest: none reported

\section{CORRESPONDING AUTHOR}

Elizabeth H. B. Lin, MD, MPH

Center for Health Studies,

Group Health Cooperative

1730 Minor Ave, Suite 1600

Seattle, WA 98101

lin.e@ghc.org

\begin{abstract}
PURPOSE Among patients with diabetes, major depression is associated with more diabetic complications, lower medication adherence, and poorer self-care of diabetes. We reported earlier that enhanced depression care reduces depression symptoms but not hemoglobin $A_{1 c}$ level. This study examined effects of depression interventions on self-management among depressed diabetic patients.
\end{abstract}

METHODS A total of 329 patients in 9 primary care clinics were randomized to an evidence-based collaborative depression treatment (pharmacotherapy, problemsolving treatment, or both in combination) or usual primary care (routine medical services). Outcome measures included the Summary of Diabetes Self-Care Activities (SDSCA), reported at baseline and 3, 6, and 12 months, and medication nonadherence as assessed by automated pharmacy refill data of oral hypoglycemic agents, lipid-lowering agents, and angiotensin-converting enzyme inhibitors. We used mixed regression models adjusted for baseline differences to compare the intervention with usual care groups at follow-up assessments.

RESULTS During the 12-month intervention period, enhanced depression care and outcomes were not associated with improved diabetes self-care behaviors (healthy nutrition, physical activity, or smoking cessation). Relative to the usual care group, the intervention group reported a small decrease in body mass index (mean difference $=0.70 \mathrm{~kg} / \mathrm{m}^{2}, 95 \% \mathrm{Cl}, 0.17$ to $1.24 \mathrm{~kg} / \mathrm{m}^{2}$ ) and a higher rate of nonadherence to oral hypoglycemic agents (mean difference $=-6.3 \%, 95 \% \mathrm{Cl},-11.91 \%$ to $-0.71 \%$ ). Adherence to lipid-lowering agents and to antihypertensive medicines was similar for the 2 groups.

CONCLUSIONS In general, diabetes self-management did not improve among the enhanced depression treatment group during a 12-month period, except for small between-group differences of limited clinical importance. Research needs to assess whether self-care interventions tailored for specific conditions, in addition to enhanced depression care, can achieve better diabetes and depression outcomes.

Ann Fam Med 2006;4:46-53. DOI: 10.1370/afm.423.

\section{INTRODUCTION}

S elf-care is a cornerstone of diabetes management. Daily practice of healthy nutrition and physical activity can slow disease progression. ${ }^{1-3}$ Adherence to medical regimens for diabetes can lessen the disease burden and reduce the morbidity and mortality associated with diabetic complications. ${ }^{4}$ Poor self-management of diabetes is, however, the norm and intensifies the burden of this epidemic condition. ${ }^{5-7}$

The prevalence of depression is roughly twice as high among diabetic patients as among the general population. ${ }^{8}$ Depressed patients with diabetes have poorer glycemic control, more severe diabetes symptoms and disability, added complications, and higher health care use relative to patients with diabetes but no depression. ${ }^{6,8-14}$ Self-management is even less adequate among diabetic patients with depression than among those without it.

Nonadherence to diabetes medications, physical inactivity, poor nutrition, and smoking are highly correlated with depression, while self-monitoring 
of blood glucose is similar in depressed and nondepressed diabetic patients. ${ }^{5}$ Poor medication adherence is related not only to worse clinical outcomes, but also to subsequent hospitalizations and increased health care costs. ${ }^{15}$ This relationship of depression and poor self-management is consistent across different socioeconomic and cultural groups. ${ }^{16,17}$

The clear association between depression, inadequate self-management, and adverse outcomes has led many to advocate for better identification and treatment of depression among diabetic patients. Thus far, cross-sectional studies have provided most of the evidence regarding the association of depression with poor diabetes self-management and adverse outcomes. Recently, McKellar and colleagues ${ }^{18}$ and Piette and colleagues ${ }^{19}$ used structural equation modeling to test the relationship between depressive symptoms, poorer self-care, and subsequent glucose dysregulation. These studies found that depression increased symptoms of glucose dysregulation through lower adherence to selfcare; however, depression did not significantly influence subsequent diabetes-related symptoms above and beyond their impact on patients' self-care behaviors.

Randomized controlled trials to improve depression among diabetic patients have had mixed effects on diabetes outcomes. ${ }^{20-24}$ Among patients with poorly controlled diabetes receiving specialty care, an earlier study of cognitive behavioral therapy and diabetes education showed a clinically significant reduction in hemoglobin $\mathrm{A}_{1 \mathrm{c}}\left(\mathrm{HbA}_{1 \mathrm{c}}\right)$ level at the 6-month follow-up when compared with a control group receiving diabetes education only. ${ }^{21}$ An unexpected finding was that intervention patients receiving cognitive behavioral therapy and diabetes education showed less self-monitoring of glucose levels relative to the education group during the intervention period. Trials comparing antidepressant pharmacotherapy with placebo found that nortriptyline therapy did not change the glycemic index among patients with diabetes and depression, ${ }^{20}$ while fluoxetine therapy was associated with a trend toward a lower $\mathrm{HbA}^{\text {ic }}$ level. ${ }^{22}$

Two recent randomized trials of systematic depression management in primary care both found a significant improvement in depression among patients with diabetes and depression, but no significant effect on glycemic control. ${ }^{23,24}$ In a study of older adults with depression and diabetes, Williams and colleagues ${ }^{23}$ reported that the intervention patients increased their physical activity relative to usual care patients. There was, however, no intervention effect on other self-management activities, and diabetic medication adherence was not assessed. In a randomized trial of a mixed-age primary care population with diabetes, Katon and colleagues ${ }^{24}$ found that a systematic depression care pro- gram significantly increased quality of depression care and reduced depressive symptoms but did not have a significant impact on glycemic control. ${ }^{24}$ We used data from this same trial to examine the impact of improved depression treatment on self-care behaviors, including adherence to diabetes medications.

\section{METHODS}

\section{Study Setting}

From March 2001 to May 2002, 9 primary care clinics of Group Health Cooperative (GHC), a prepaid health plan enrolling about 500,000 Washington State residents, participated in this study. Demographic characteristics of GHC enrollees are representative of the Seattle-area population. Board-certified family medicine physicians and internists provide the majority of medical services for GHC enrollees. The Human Subjects Review Committees of Group Health Cooperative and the University of Washington approved the study procedures.

\section{Sample Recruitment and Randomization}

Enrollees aged 18 years or older were recruited from the GHC diabetes registry that included individuals with any of the following: (1) at least 2 fasting plasma glucose levels of greater than $126 \mathrm{mg} / \mathrm{dL}$ or a random plasma glucose level of greater than $200 \mathrm{mg} / \mathrm{dL},(2)$ current use of any diabetic medication, and (3) an inpatient or outpatient diagnosis of diabetes. Exclusion criteria included the following: not having diabetes, having gestational diabetes, cognitive impairment, terminal illness, disenrollment or planned disenrollment from the health plan, language or hearing barrier, psychotic disorder, bipolar disorder, use of mood-stabilizing or antipsychotic medication, and current care by a psychiatrist.

A questionnaire was sent to 7,841 eligible individuals with diabetes. In all, $62 \%$ responded, and 4,839 were enrolled in the cohort epidemiologic study. To be eligible for the randomized trial, participants were required to have a score of 10 or higher on the Patient Health Questionnaire-9 (PHQ-9) ${ }^{25}$ at the initial screening and evidence of persistent depression as measured by a mean item score of 1.1 or higher on the Hopkins Symptom Checklist-20 (SCL-20) 26 weeks later. Patients were not excluded if they had taken antidepressants in the previous 3 months as long as they had persistent depressive symptoms. Among the 375 patients eligible for the depression and diabetes clinical trial, 46 declined randomization. A computer algorithm randomly assigned 164 patients to the intervention group and 165 patients to the usual care group. A detailed description of sample recruitment is described in our earlier publication. ${ }^{24}$ 


\section{Main Outcome Measures}

\section{Self-Care for Diabetes}

We used a recently revised version of the Summary of Diabetes Self-Care Activities (SDSCA) ${ }^{27}$ to assess diabetes self-management behaviors for diet, exercise, blood glucose testing, foot checks, and smoking. The SDSCA is a brief, reliable, valid, and multidimensional measure of diabetes self-care behaviors based on selfreport. Patients reported how many days in the previous week they engaged in a certain activity.

\section{Medication Adherence}

The GHC automated pharmacy database has recorded all prescriptions filled by enrollees since 1976 . We used computerized records of pharmacy refills to derive measures of adherence to oral hypoglycemic agents, antihypertensive agents, and lipid-lowering medications for the year before each patient's interview date. For each prescription, the days of medication supply were added to the date that the prescription was filled. This second date was considered the expected refill date. If the next refill was obtained after the expected refill date, then the number of days between the expected refill date and the next refill date (days during which a patient lacked oral hypoglycemic, lipid-lowering, or antihypertensive medicines) were labeled as nonadherent days. The percentage of days a patient was nonadherent was then estimated by dividing the total number of nonadherent days in the previous year (numerator) by the total number of days the patient was prescribed oral hypoglycemic agents, including the nonadherent days (denominator). The percentage of days nonadherent allowed us to combine information across patients with varying lengths of follow-up.

The observation window, that is, the number of days a patient was prescribed oral hypoglycemic agents in the year, was estimated to be either 365 for patients already using these medications at the beginning of the year or the number of days between the first prescription and the interview date for patients started on these medications during the year. Patients whose first oral hypoglycemic agent prescription had not been exhausted by the interview date were excluded. A similar measure, using automated pharmacy data, was used in an earlier study to evaluate nonadherence with antihypertensive medications. ${ }^{28}$

\section{Study Groups}

\section{Intervention: Collaborative Depression Care} Management

Our year-long intervention focused on enhancing depression treatment, not on diabetes management. Nurses received training on depression diagnosis and pharmacotherapy, behavioral activation, and problem-solving treat- ment for primary care, similar to the intervention developed for the IMPACT study. ${ }^{29}$ Nurses collaborated with behavioral health consultants and primary care physicians to provide individualized management of depression care according to patient preference and treatment response. Patients were offered an initial choice of 2 evidencebased treatments: antidepressant medication or problem-solving treatment. The goal of depressive symptom remission was achieved through a stepped care approach that augmented pharmacotherapy, problem-solving treatment, or both with psychiatric consultations and group and community services. Nurse care managers supported depression self-management through behavioral activation, such as exercise, goal setting, and problem solving. Neither diabetes education nor diabetes clinical management was a component of this depression intervention; however, patients could choose physical activity or healthy nutrition for behavioral activation, or could identify another diabetes self-care activity as a problem to tackle in a problem-solving treatment session.

Treatment included an initial hour-long visit followed by twice-monthly, half-hour appointments (telephone and in-person) in the acute phase of treatment (0-12 weeks). Once patients experienced a substantial (at least 50\%) reduction in clinical symptoms, the nurse began continuation phase treatment, which consisted of monthly scheduled telephone contacts. For patients who had persistent symptoms or who were socially isolated, nurses offered monthly continuation groups instead of monthly telephone calls. Each nurse was supervised twice per month by a team of a psychiatrist (WK, GES, or EW), psychologist (EJL), and family physician (EHBL) in the review of new cases and patient progress. Nurses interacted regularly (via written notes and verbally) with the primary care physician treating the patient. Our earlier publication details the intervention design and procedures. ${ }^{24}$

\section{Usual Care}

Usual care patients were advised to consult their primary care physician regarding depression treatment. Primary care physicians at GHC frequently prescribe antidepressant medication and can refer patients to the GHC Mental Health Services. Both intervention and usual care patients could also self-refer to a GHC mental health clinician. Primary care physicians provide most of the diabetes care in GHC with occasional support from diabetes consultants for complex patients.

\section{Statistical Analyses}

We used $t$ tests to compare characteristics of intervention and usual care groups at baseline. We used regression analysis to model outcomes as a function of intervention status while adjusting for potential con- 
founders (age, sex, race, education, comorbid disease severity, diabetic complications, and insulin use) and the corresponding baseline measure. For example, models describing physical activity at follow-up adjusted for physical activity at baseline in addition to potential confounders. We estimated regression models using generalized estimating equations (GEE) with robust covariance estimation to adjust variance estimates for the clustering of patients within primary care physician and of physicians within clinics. Models for outcomes measured at 3, 6, and 12 months used all available data and adjusted for repeated measures within patients over time. We used logistic regression for dichotomous outcomes and linear regression for ordinal outcomes and continuous outcomes (ie, adherence measures).

\section{RESULTS}

\section{Sample}

Among the 329 randomized patients-164 in the intervention group and 165 in the usual care group-respective rates of completion of assessments were $91 \%$ and $93.3 \%$ at 3 months, $87.8 \%$ and $90.9 \%$ at 6 months, and $88.5 \%$ and $86.1 \%$ at 12 months. In all, $80.5 \%$ of intervention patients and $79.4 \%$ of usual care patients completed all assessments during 1 year of follow-up.

\section{Baseline Characteristics}

The intervention and usual care groups were demographically similar and clinically balanced at baseline with respect to diabetes and depression measures (Table 1). This primary care population with diabetes and coexisting depression had a mean age of 58.5 years; two thirds were women, and one fifth were racial or ethnic minorities. Patients predominantly had type 2 diabetes, with a mean $\mathrm{HbA}_{1 \mathrm{c}}$ value of $8.0 \%$, and 1.5 diabetic complications. About 40\% required insulin treatment. A majority of the sample had chronic or recurrent depression (dysthymia or 3 or more previous episodes of depression). Approximately two thirds met criteria for major depression and had moderate depression severity as measured by SCL$20 .{ }^{26}$ One half of patients had been treated with an antidepressant medication in the preceding 3 months.

\section{Intervention Participation and Depression Outcomes}

Almost all of the intervention patients (97.6\%) completed the initial visit; among the intervention group, only 14 patients $(8.5 \%)$ received neither antidepressant nor problem-solving treatment. As reported previously, relative to usual care patients, intervention patients had more adequate antidepressant pharmacotherapy over a 1 -year period and less severe depression over time. ${ }^{24}$

\section{Diabetes Self-Care}

There were gaps in quality of self-care activities at baseline for both treatment groups (Table 2). Practicing healthy nutrition or following a recommended diet was reported for about one half the number of days in the preceding week. This largely sedentary and overweight population reported that they engaged in at least 30 minutes of continuous activity for only 2 to 3 days in the previous week. Specific exercise sessions were carried out on fewer than 2 days in the previous week. The proportion of cigarette smokers was lower (but not significantly so) in the intervention group (18\%, $\mathrm{SD}=11.1 \%)$ than in the usual care group $(28 \%, \mathrm{SD}=$ $17.3 \%)$. The only significant baseline differences in diabetes self-care found between usual care and intervention groups were a slightly higher number of days with exercise sessions $(P<.005)$ and a slightly lower body mass index $(\mathrm{BMI})(P<.03)$ among intervention patients relative to usual care patients.

Overall, there was no difference between intervention and usual care in diabetes self-management during the 12-month period (Table 2). When controlling for baseline differences, the intervention group maintained a lower BMI at the 1 -year follow-up $(P<.01)$. No difference was observed between the 2 groups in healthy
Table 1. Demographic and Baseline Clinical Characteristics

\begin{tabular}{|c|c|c|}
\hline Characteristic & $\begin{array}{c}\text { Usual Care } \\
(n=165) \\
\% \text { (No.) }\end{array}$ & $\begin{array}{c}\text { Intervention } \\
(\mathrm{n}=164) \\
\% \text { (No.) }\end{array}$ \\
\hline \multicolumn{3}{|l|}{ Dichotomous characteristics } \\
\hline Female & $64.8(107)$ & $65.2(107)$ \\
\hline Married & $54.9(90)$ & $54.8(94)$ \\
\hline Employed (full- or part-time) & $45.2(71)$ & $54.2(84)$ \\
\hline White & $81.1(133)$ & $75.2(115)$ \\
\hline Type 2 diabetes & $95.8(158)$ & $96.3(157)$ \\
\hline Taking insulin & $43.0(71)$ & $38.4(63)$ \\
\hline Major depression & $69.1(114)$ & $62.6(102)$ \\
\hline Lifetime dysthymia & $70.3(116)$ & $67.5(110)$ \\
\hline$\geq 3$ previous episodes of depression & $60.5(92)$ & $68.6(107)$ \\
\hline \multirow[t]{2}{*}{ Antidepressant use in previous 3 months } & $54.0(101)$ & $46.0(86)$ \\
\hline & Mean (SD) & Mean (SD) \\
\hline \multicolumn{3}{|l|}{ Continuous characteristics } \\
\hline Age, y & $58.1(12.0)$ & $58.6(11.8)$ \\
\hline $\mathrm{HbA}_{1 \mathrm{c}}, \%$ & $8.0(1.5)$ & $8.0(1.6)$ \\
\hline Number of diabetic complications & $1.5(1.4)$ & $1.5(1.3)$ \\
\hline Baseline SCL-20 score & $1.6(0.5)$ & $1.7(0.5)$ \\
\hline
\end{tabular}




\begin{tabular}{|c|c|c|c|}
\hline Activity & $\begin{array}{c}\text { Usual Care } \\
(n=165) \\
\text { Mean (SD)* }\end{array}$ & $\begin{array}{c}\text { Intervention } \\
(n=164) \\
\text { Mean (SD)* }\end{array}$ & $\begin{array}{l}\text { Adjusted Mean } \\
\text { Difference } \\
(95 \% \mathrm{Cl})^{\dagger}\end{array}$ \\
\hline \multicolumn{4}{|c|}{$\begin{array}{l}\text { Generally healthy diet, } \\
\text { number of days }\end{array}$} \\
\hline Baseline & $3.7(2.1)$ & $3.7(2.1)$ & - \\
\hline $3 \mathrm{mo}$ & $4.3(2.0)$ & $4.1(1.9)$ & $0.15(-0.15$ to 0.45$)$ \\
\hline $6 \mathrm{mo}$ & $4.4(1.9)$ & $4.2(2.0)$ & $0.07(-0.21$ to 0.35$)$ \\
\hline $12 \mathrm{mo}$ & $4.5(2.1)$ & $4.5(1.9)$ & $-0.01(-0.56$ to 0.54$)$ \\
\hline \multicolumn{4}{|c|}{$\begin{array}{l}\text { Recommended diet, } \\
\text { number of days }\end{array}$} \\
\hline Baseline & $3.2(1.6)$ & $3.5(1.7)$ & - \\
\hline $3 \mathrm{mo}$ & $3.6(1.7)$ & $3.8(1.8)$ & $-0.07(-0.34$ to 0.20$)$ \\
\hline $6 \mathrm{mo}$ & $3.8(1.7)$ & $3.9(1.8)$ & $-0.01(-0.22$ to 0.20$)$ \\
\hline $12 \mathrm{mo}$ & $3.8(1.8)$ & $4.1(1.9)$ & $-0.05(-0.42$ to 0.32$)$ \\
\hline \multicolumn{4}{|c|}{$\begin{array}{l}\text { Physical activity ( } \geq 30 \mathrm{~min} \text { ), } \\
\text { number of days }\end{array}$} \\
\hline Baseline & $2.3(2.2)$ & $2.6(2.4)$ & - \\
\hline $3 \mathrm{mo}$ & $2.7(2.4)$ & $2.7(2.5)$ & $0.08(-0.43$ to 0.59$)$ \\
\hline $6 \mathrm{mo}$ & $2.4(2.3)$ & $2.3(2.3)$ & $0.19(-0.21$ to 0.60$)$ \\
\hline $12 \mathrm{mo}$ & $2.6(2.5)$ & $2.7(2.4)$ & $-0.12(-0.50$ to 0.26$)$ \\
\hline \multicolumn{4}{|c|}{$\begin{array}{l}\text { Exercise session, } \\
\text { number of days }\end{array}$} \\
\hline Baseline $^{\ddagger}$ & $1.2(1.8)$ & $1.9(2.2)$ & - \\
\hline $3 \mathrm{mo}$ & $1.7(2.4)$ & $1.9(2.3)$ & $-0.12(-0.84$ to 0.59$)$ \\
\hline $6 \mathrm{mo}$ & $1.7(2.2)$ & $1.6(2.2)$ & $0.19(-0.37$ to 0.76$)$ \\
\hline $12 \mathrm{mo}$ & $1.6(2.1)$ & $1.9(2.3)$ & $-0.19(-0.57$ to 0.19$)$ \\
\hline \multicolumn{4}{|c|}{ BMI, kg/m² } \\
\hline Baseline $^{\S}$ & $36.3(11.1)$ & $33.9(8.6)$ & - \\
\hline $12 \mathrm{mo}^{9}$ & $36.1(10.0)$ & $33.0(7.9)$ & 0.70 (0.17 to 1.24$)$ \\
\hline \multicolumn{4}{|c|}{$\begin{array}{l}\text { * Means and SDs are unadjusted. } \\
\text { † Adjusted mean differences and } 95 \% \text { Cls are based on regression models that adjusted for the baseline value, } \\
\text { age, sex, race, education, comorbid conditions other than diabetes and depression, complications, and use of } \\
\text { insulin, with variance estimates that accounted for clustering of measurements within patients, patients within phy- } \\
\text { sicians, and physicians within clinics. } \\
\text { f Intervention and usual care groups differ significantly, with adjustment, } P \geq .005 \text {. } \\
\text { § Intervention and usual care groups differ significantly, without adjustment, } P \geq .05 \\
\text { I Intervention and usual care groups differ significantly, with adjustment, } P \geq .01 \text {. }\end{array}$} \\
\hline
\end{tabular}

about $2-1 / 2$ to $3-1 / 2$ months. At baseline, there were no significant differences in adherence between intervention and usual care groups. After controlling for baseline status, the depression care intervention group had a slightly higher rate of nonadherence to oral hypoglycemic agents compared with the usual care group during the 12-month period $(P<.03)$. We did not find significant differences in adherence to ACE inhibitors or lipidlowering medication in intervention group patients relative to their usual care counterparts.

\section{DISCUSSION}

In an earlier study, we found that enhancing depression care among patients with diabetes and depression increased adherence to antidepressant pharmacotherapy and problem-solving treatment, and reduced depressive symptoms, ${ }^{24}$ but glycemic control in the intervention and usual care groups was similar. Examining the effects of the intervention on diabetes self-care behaviors showed that improved quality of depression care and depression outcomes were not associated with increases in healthy nutrition, physical activity, or smoking cessation, or increased adherence to ACE

nutrition, following a recommended diet, days with 30 or more minutes of continuous physical activity, days with specific exercise sessions, or smoking status (18\%, $\mathrm{SD}=12.3 \%$ for the intervention group vs $24 \%, \mathrm{SD}=$ $16.9 \%$ for the usual care group; $95 \%$ confidence interval for the odds ratio $=0.4-4.9$ ).

\section{Medication Adherence}

The rate of nonadherence to oral hypoglycemic and lipid-lowering agents and angiotensin-converting enzyme (ACE) inhibitors was quite high among both intervention and usual care patients, ranging from roughly $20 \%$ to $30 \%$ (Table 3 ). During the 12 -month intervention (postrandomization) period, diabetic patients with depression did not have medication to control diabetes or to prevent complications for inhibitors or lipid-lowering agents. Small but statistically significant between-group differences were seen in adherence to oral hypoglycemic agents and in BMI during the 12 -month period. Compared with patients receiving usual care, intervention patients reported lower BMI but poorer adherence to oral hypoglycemic agents; however, these findings were small and of uncertain clinical importance.

Limitations of our study include unknown generalizability of a sample consenting to a randomized controlled trial to other patients with diabetes and depression. Pharmacy refill records were used to measure adherence; these data indicate only prescriptions that were filled, not medications actually taken. ${ }^{30}$ Our meaNonadherence rates of $20 \%$ or higher, as reported in this sure may even underestimate actual patient adherence. 


\begin{tabular}{|c|c|c|c|}
\hline Medication & $\begin{array}{c}\text { Usual Care } \\
\% \text { of Days } \\
\text { Mean (SD)* } \\
\text { [No. of Patients] }\end{array}$ & $\begin{array}{c}\text { Intervention } \\
\% \text { of Days } \\
\text { Mean (SD)* } \\
\text { [No. of Patients] }\end{array}$ & $\begin{array}{l}\text { Adjusted Mean } \\
\text { Difference } \\
\% \text { of Days } \\
(95 \% \mathrm{Cl})^{\dagger}\end{array}$ \\
\hline \multicolumn{4}{|c|}{ Oral hypoglycemic agent } \\
\hline Prerandomization & $\begin{array}{c}22.9(24.0) \\
{[103]}\end{array}$ & $\begin{array}{l}19.8(21.3) \\
{[103]}\end{array}$ & \\
\hline Postrandomization ${ }^{\ddagger}$ & $\begin{array}{c}24.0(24.7) \\
{[103]}\end{array}$ & $\begin{array}{l}28.2(28.9) \\
{[103]}\end{array}$ & $\begin{array}{c}-6.3 \\
(-11.91 \text { to }-0.71)\end{array}$ \\
\hline \multicolumn{4}{|l|}{ ACE inhibitor } \\
\hline Prerandomization & $\begin{array}{c}29.7(29.3) \\
{[65]}\end{array}$ & $\begin{array}{c}27.4(27.1) \\
{[54]}\end{array}$ & \\
\hline Postrandomization & $\begin{array}{c}18.9(17.4) \\
{[52]}\end{array}$ & $\begin{array}{c}24.2(22.7) \\
{[59]}\end{array}$ & $\begin{array}{c}-2.5 \\
(-8.69 \text { to } 3.70)\end{array}$ \\
\hline \multicolumn{4}{|c|}{ Lipid-lowering agent } \\
\hline Prerandomization & $\begin{array}{c}24.5(23.0) \\
{[52]}\end{array}$ & $\begin{array}{c}29.3(26.7) \\
{[50]}\end{array}$ & \\
\hline Postrandomization & $\begin{array}{c}27.7(24.0) \\
{[63]}\end{array}$ & $\begin{array}{c}28.8(27.1) \\
{[54]}\end{array}$ & $\begin{array}{c}-0.2 \\
(-7.23 \text { to } 6.76)\end{array}$ \\
\hline \multicolumn{4}{|c|}{$\mathrm{Cl}=$ confidence interval; $\mathrm{ACE}=$ angiotensin-converting enzyme. } \\
\hline \multicolumn{4}{|c|}{$\begin{array}{l}\text { * Means and SDs are unadjusted. } \\
\text { † Estimated differences and } 95 \% \text { Cls are based on regression models that adjusted for the baseline value, age, sex, } \\
\text { race, education, comorbid conditions other than diabetes and depression, complications, and use of insulin, with vari- } \\
\text { ance estimates that account for clustering of measurements within patients, patients within physicians, and physicians } \\
\text { within clinics. } \\
\text { f Intervention and usual care groups differ significantly, } P<03 \text {. }\end{array}$} \\
\hline
\end{tabular}

2 hours each day is required for performing the American Diabetes Association-recommended self-care tasks among patients taking oral hypoglycemic agents. ${ }^{34}$ Physical activity and healthy nutrition are the most time-consuming daily tasks. This challenge was suggested by the unexpected results of Lustman and colleagues $^{21}$ that adding cognitive behavioral therapy to diabetes education had a significantly deleterious effect on self-monitoring of blood glucose during the 10 -week treatment period. They postulated that perhaps cognitive behavioral therapy homework, such as recognizing maladaptive thought patterns on top of an already complex diabetes education regimen for self-management, was more than the patients could handle. Our finding that, during enhancement of depression management, intervention patients showed lower adherence to oral hypoglycemic medicines also highlights the complexity and challenge patients face in managing multiple medical conditions on a daily basis.

Competing demands is also a challenging reality for primary care physicians. ${ }^{37}$ Coexisting physical conditions compete with and overshadow the needs of depression care in brief primary care encounters. ${ }^{38}$ One must therefore be vigilant to limit the number of new interventions physicians are recommended to provide; otherwise, successful management of one chronic illness (eg, antidepressant medication adherence) may occur at the expense of another clinically important behavior (eg, antidiabetic medication adherence). Encouraging patients to identify 1 top-priority self-care behavior of their preference that they feel is most feasible may be more effective than expecting physicians and patients to adopt multiple behavior changes simultaneously.

Findings of this study do not imply that depression care is not useful for improving diabetes self-management or outcomes. Better identification and care of depression among diabetic patients may be the first step toward more effective diabetes self-management. Piette and colleagues ${ }^{19}$ proposed a schema of pathways linking major depression to adverse physiologic and quality-oflife outcomes for diabetes, mediated by poor self-management. Perhaps major depression, poor self-care, and 
adverse outcomes are linked in a bidirectional and reciprocal manner, thus resulting in adverse outcomes. Just as effective diabetes management may be compromised by depression and associated characteristics, such as pessimism and fatigue, effective depression management may also be undermined by symptoms of poor diabetes control, such as neuropathic pain and functional disability. Maximal benefit of treating depression for improving broader outcomes is likely to require direct targeting of specific behaviors most relevant to the patient's role in managing their coexisting chronic illness.

Because the population is aging, most patients seeking care from primary care physicians will have more than 1 chronic illness. A coordinated therapeutic approach that considers coexisting chronic diseases will be essential. Patients with depression and co-occurring medical illnesses require interventions that advance beyond single-disease case management, such as nurse case managers trained to manage care for related chronic conditions (eg, diabetes and heart disease) and coexisting depression in general medical settings. ${ }^{39}$ Focusing patients on disease management of 1 chronic illness can have unintended adverse effects on management of other important disorders. Further research is needed to determine whether integrated diabetes and depression care management, including specific support for diabetes medication adherence and self-care activities, as well as systematic depression care, can help patients achieve better psychological and diabetes outcomes.

To read or post commentaries in response to this article, see it online at http://www.annfammed.org/cgi/content/full/4/1/46.

Key words: Diabetes mellitus; depression; self-care; exercise; patient nonadherence; mental health; health care delivery; health services research; primary care

Submitted March 24, 2005; submitted, revised, August 22, 2005; accepted September 13, 2005.

Presented at the 63rd Annual Scientific Meeting of the American Psychosomatic Society, March 4, 2005, Vancouver, British Columbia.

Funding support: Supported by grants MH 41739 and MH 01643 from the National Institute of Mental Health, Services Division, Bethesda, Md.

\section{References}

1. Norris SL, Engelgau MM, Narayan KM. Effectiveness of self-management training in type 2 diabetes: a systematic review of randomized controlled trials. Diabetes Care. 2001;24:561-587.

2. Glasgow RE, Boles SM, McKay HG, Feil EG, Barrera M Jr. The D-Net diabetes self-management program: long-term implementation, outcomes, and generalization results. Prev Med. 2003;36:410-419.

3. Newman S, Steed L, Mulligan K. Self-management interventions for chronic illness. Lancet. 2004;364:1523-1537.

4. American Diabetes Association. Standards of medical care in diabetes. Diabetes Care. 2005;28(Suppl 1):S4-S36.
5. Lin EH, Katon W, Von Korff M, et al. Relationship of depression and diabetes self-care, medication adherence, and preventive care. Diabetes Care. 2004;27:2154-2160.

6. Ciechanowski PS, Katon WJ, Russo JE, Hirsch IB. The relationship of depressive symptoms to symptom reporting, self-care and glucose control in diabetes. Gen Hosp Psychiatry. 2003;25:246-252.

7. Cramer JA. A systematic review of adherence with medications for diabetes. Diabetes Care. 2004;27:1218-1224.

8. Katon W, von Korff M, Ciechanowski $\mathrm{P}$, et al. Behavioral and clinical factors associated with depression among individuals with diabetes. Diabetes Care. 2004;27:914-920.

9. Gary TL, Crum RM, Cooper-Patrick L, Ford D, Brancati FL. Depressive symptoms and metabolic control in African-Americans with type 2 diabetes. Diabetes Care. 2000;23:23-29.

10. de Groot M, Anderson R, Freedland KE, Clouse RE, Lustman PJ. Association of depression and diabetes complications: a meta-analysis. Psychosom Med. 2001;63:619-630.

11. Lustman PJ, Anderson RJ, Freedland KE, et al. Depression and poor glycemic control: a meta-analytic review of the literature. Diabetes Care. 2000;23:934-942

12. Ludman E, Katon W, Bush T, et al. Behavioural factors associated with symptom outcomes in a primary care-based depression prevention intervention trial. Psychol Med. 2003;33:1061-1070.

13. Von Korff M, Katon W, Lin EH, et al. Work disability among individuals with diabetes. Diabetes Care. 2005;28:1326-1332.

14. Simon GE, Katon WJ, Lin EH, et al. Diabetes complications and depression as predictors of health service costs. Gen Hosp Psychiatry. 2005;27:344-351.

15. Lau DT, Nau DP. Oral antihyperglycemic medication nonadherence and subsequent hospitalization among individuals with type 2 diabe tes. Diabetes Care. 2004;27:2149-2153.

16. Park $H$, Hong $Y$, Lee $H$, Ha $E$, Sung $Y$. Individuals with type 2 diabetes and depressive symptoms exhibited lower adherence with selfcare. J Clin Epidemiol. 2004;57:978-984.

17. Lerman I, Lozano L, Villa AR, et al. Psychosocial factors associated with poor diabetes self-care management in a specialized center in Mexico City. Biomed Pharmacother. 2004;58:566-570.

18. McKellar JD, Humphreys K, Piette JD. Depression increases diabetes symptoms by complicating patients' self-care adherence. Diabetes Educ. 2004;30:485-492.

19. Piette JD, Richardson C, Valenstein M. Addressing the needs of patients with multiple chronic illnesses: the case of diabetes and depression. Am J Manag Care. 2004;10:152-162.

20. Lustman PJ, Griffith LS, Clouse RE, et al. Effects of nortriptyline on depression and glycemic control in diabetes: results of a doubleblind, placebo-controlled trial. Psychosom Med. 1997;59:241-250.

21. Lustman PJ, Griffith LS, Freedland KE, Kissel SS, Clouse RE. Cognitive behavior therapy for depression in type 2 diabetes mellitus: a randomized, controlled trial. Ann Intern Med. 1998;129:613-621.

22. Lustman PJ, Freedland KE, Griffith LS, Clouse RE. Fluoxetine for depression in diabetes: a randomized double-blind placebo-controlled trial. Diabetes Care. 2000;23:618-623.

23. Williams JW Jr, Katon W, Lin EH, et al. The effectiveness of depres sion care management on diabetes-related outcomes in older patients. Ann Intern Med. 2004;140:1015-1024.

24. Katon WJ, Von Korff M, Lin EH, et al. The Pathways Study: a randomized trial of collaborative care in patients with diabetes and depression. Arch Gen Psychiatry. 2004;61:1042-1049.

25. Spitzer RL, Kroenke K, Williams JB. Validation and utility of a selfreport version of PRIME-MD: the PHQ primary care study. Primary Care Evaluation of Mental Disorders. Patient Health Questionnaire. JAMA. 1999;282:1737-1744. 
26. Derogatis L, Rickels K, Uhlenhuth E, Covi L. The Hopkins Symptom Checklist: a measure of primary symptom dimensions. In: Pinchot $P$, ed. Psychological Measurements in Psychopharmacology: Problems in Pharmacopsychiatry. Basil, Switzerland: Kargerman; 1974.

27. Toobert DJ, Hampson SE, Glasgow RE. The Summary of Diabetes Self-Care Activities measure: results from 7 studies and a revised scale. Diabetes Care. 2000;23:943-950.

28. Wang PS, Bohn RL, Knight $E$, et al. Noncompliance with antihypertensive medications: the impact of depressive symptoms and psychosocial factors. J Gen Intern Med. 2002;17:504-511.

29. Unutzer J, Katon W, Callahan CM, et al. Collaborative care management of late-life depression in the primary care setting: a randomized controlled trial. JAMA. 2002;288:2836-2845.

30. Pladevall M, Williams LK, Potts LA, et al. Clinical outcomes and adherence to medications measured by claims data in patients with diabetes. Diabetes Care. 2004;27:2800-2805.

31. Gaede $P$, Vedel $P$, Larsen $N$, et al. Multifactorial intervention and cardiovascular disease in patients with type 2 diabetes. $N$ Engl J Med. 2003;348:383-393.

32. Knowler WC, Barrett-Connor E, Fowler SE, et al. Reduction in the incidence of type 2 diabetes with lifestyle intervention or metformin. N Engl J Med. 2002;346:393-403.
33. Diabetes Prevention Program (DPP) Research Group. The Diabetes Prevention Program (DPP): description of lifestyle intervention. Diabetes Care. 2002;25:2165-2171.

34. Russell LB, Suh DC, Safford MA. Time requirements for diabetes selfmanagement: too much for many? J Fam Pract. 2005;54:52-56.

35. Herman WH, Hoerger TJ, Brandle $M$, et al. The cost-effectiveness of lifestyle modification or metformin in preventing type 2 diabetes in adults with impaired glucose tolerance. Ann Intern Med. 2005; 142:323-332.

36. Diabetes Prevention Program Research Group. Within-trial cost-effectiveness of lifestyle intervention or metformin for the primary prevention of type 2 diabetes. Diabetes Care. 2003;26:2518-2523.

37. Klinkman MS. Competing demands in psychosocial care: a model for the identification and treatment of depressive disorders in primary care. Gen Hosp Psychiatry. 1997;19:98-111.

38. Rost K, Nutting P, Smith J, et al. The role of competing demands in the treatment provided primary care patients with major depression. Arch Fam Med. 2000;9:150-154.

39. de Gruy F 3rd. Depression research in primary care: pushing the field forward. Ann Fam Med. 2005;3:3-6.

\section{CHANGE-OF-ADDRESS FORM FAMMILY MEDICINE}

Please complete this form and mail to the following address or fax to Annals Circulation at 913-906-6080:

Annals of Family Medicine, Circulation Department, 11400 Tomahawk Creek Pkwy, Leawood, KS 66211-2672

Check if member of sponsoring organization: $\square$ AAFP $\square$ ABFM $\square$ STFM $\square$ ADFM $\square$ AFMRD $\square$ NAPCRG

ID number from label on your journal cover

OLD Information (Please print.)

Name

Company (if applicable)

Address (Street plus Apt or Ste)

\begin{tabular}{lc}
\hline City & State \\
\hline Country & Postal Code (9-digit ZIP for US)
\end{tabular}

Telephone

Fax

E-Mail
NEW Information (Please print.)

\begin{tabular}{ll}
\hline Name \\
\hline Company (if applicable) & \\
\hline Address (Street plus Apt or Ste) & State \\
\hline City & Postal Code (9-digit ZIP for US) \\
\hline Country & Fax \\
\hline Telephone & \\
\hline E-Mail &
\end{tabular}

